Ann. Biol. anim. Bioch. Biophys., 1978, 18 (1), 175-180.

\title{
Métabolisme et activité du 25-hydroxycholécalciférol dans les chondrocytes en culture
}

\author{
par Michèle GARABEDIAN, Marie-Thérèse CORVOL, Thi Minh NGUYEN,
} Sonia BALSAN.

Unité INSERM 30 ef Equipe de Recherche CNRS 126,

Hôpital des Enfonts Malades 149, rue de Sèvres, 75015 Paris.

Summary. Mefabolism and activity of 25-hydroxycholecalciferol in chondrocyfe culture.

Chondrocytes isolated from the articular and growth plate cartilage of prepubertal rabbits were grown in culture to study the metabolism of $25-(\mathrm{OH}) \mathrm{D}_{3}$. A polar derivative of 25- $(\mathrm{OH}) \mathrm{D}_{3}$ was detected by Sephadex LH 20 chromatography of the cell chloroform extracts as early as $15 \mathrm{~min}$ after $25-(\mathrm{OH}) \mathrm{D}_{3}$ addition. This derivative comigrated with synthetic 24,25-(OH $)_{2} \mathrm{D}_{3}$ on Sephadex $\mathrm{LH} 20$ and high-pressure liquid chromatographies. Both substances were sensitive to periodate oxydation. The 25- $(\mathrm{OH}) \mathrm{D}_{3}$ cartilage polar derivative as well as the synthetic $24,25-(\mathrm{OH})_{2} \mathrm{D}_{3}$ stimulated the incorporation of ${ }^{35} \mathrm{SO}_{4}$ into cells and medium proteoglycans at very low concentrations $\left(3.10^{-13}\right.$ to $\left.3.10^{-11} \mathrm{M}\right)$. $25-(\mathrm{OH}) \mathrm{D}_{3}$ was active on the same system ; however, one thousand times higher concentrations $\left(3.10^{-9}\right.$ to $\left.3.10^{-8} \mathrm{M}\right)$ were required to obtain that biological effect. These data suggest the ability of cartilage cells to transform $25-(\mathrm{OH}) \mathrm{D}_{3}$ into $24,25-(\mathrm{OH})_{2} \mathrm{D}_{3}$ and their possible sensitivity to the action of this dihydroxyderivative.

Le métabolisme du 25-hydroxycholécalciférol $\left(25-(\mathrm{OH}) \mathrm{D}_{3}\right)$ a été étudié in vivo tant chez l'homme que chez l'animal. Ces études ont montré que le $25-(\mathrm{OH}) \mathrm{D}_{3}$ se transforme en 24,25-dihydroxycholécalciférol $\left(24,25-(\mathrm{OH})_{2} \mathrm{D}_{3}\right)$ et en 1,25-dihydroxycholécalciférol $\left(1,25-(\mathrm{OH})_{2} \mathrm{D}_{3}\right)$ dans le rein (Deluca, 1976). Cependant la présence de $24,25-(\mathrm{OH})_{2} \mathrm{D}_{3}$ dans le sang de sujets anéphriques (tabl. 1) ainsi que la transformation

TABLEAU 1

Concentrations sériques en 25-(OH) $D_{3}$ ef $24,25-(\mathrm{OH})_{2} D_{3}$ chez l'enfant

\begin{tabular}{lcc}
\hline & $\begin{array}{c}25-(\mathrm{OH}) \mathrm{D}_{3} \\
\mathrm{ng} / \mathrm{ml}\end{array}$ & $\begin{array}{c}24,25-(\mathrm{OH})_{2} \mathrm{D}_{3} \\
\mathrm{ng} / \mathrm{ml}\end{array}$ \\
\hline Enfants normaux (15 cas) $\ldots$ & $19,5 \pm 2,6$ & $1,53 \pm 0,20$ \\
Enfants anéphriques (11 cas) & $37,4 \pm 5,5$ & $0,83 \pm 0,06$ \\
\hline
\end{tabular}

Après extraction par un mélange chloroforme-méthanol de $0,5 \mathrm{ml}$ de sérum, les dérivés de la vitamine $D$ contenus dans la phase chloroformique ont été séparés par chromatographie sur gel de Sephadex $\mathrm{LH} 20$. Les concentrations en $25-(\mathrm{OH}) \mathrm{D}_{3}$ et en $24,25-(O H)_{2} D_{3}$ ont été séparément déterminées par liaison compétitive sur une protéise sérique de rat carencé en vitamine $D$ (Preece ef al., 1974). 
du 25-(OH) $D_{3}$ en 24,25-(OH $)_{2} D_{3}$ chez les patients (Gray ef al., 1974) ef chez les rats néphrectomisés (Garabedian ef al., 1974) laissent supposer l'existence d'une 25$(\mathrm{OH}) \mathrm{D}_{3}$-24-hydroxylase extra-rénale. Cette hydroxylase a été recherchée par l'incubation in vitro, en présence de $25-(\mathrm{OH}) \mathrm{D}_{3}$ tritié, de divers tissus prélevés sur des lapins au sevrage : rein, foie, muscles des membres inférieurs, corticale des diaphyses tibiales et cartilage de croissance et articulaire. Parmi ces tissus, seuls le rein et le cartilage (quel que soit son type), sont capables de transformer le $25-(\mathrm{OH}) \mathrm{D}_{3}$ en un dérivé migrant dans la région du $24,25-(\mathrm{OH})_{2} \mathrm{D}_{3}$ lors de chromatographie sur gel de Sephadex LH 20 (Garabedian et al., 1976). La présente investigation a été menée pour rechercher si les cellules cartilagineuses en culture possédaient la même capacité que le tissu cartilagineux entier. De plus, ce système de chondrocytes en culture présente l'intérêł de permettre l'étude in vitro de l'action de substances sur le métabolisme du cartilage. La publication de travaux sur l'activité in vitro de la vitamine $D_{3}$ sur le métabolisme du cartilage étant pratiquement inexistante, le système des chondrocytes en culture a donc été utilisé pour tester l'éventuelle action biologique du cholécalciférol du $25-(\mathrm{OH}) \mathrm{D}_{3}$ et du $24,25-(\mathrm{OH})_{2} \mathrm{D}_{3}$. Cet effet a été mesuré par la stimulation de l'incorporation de soufre marqué dans les protéoglycannes sécrétés par les chondrocyłes.

\section{Matériel et méthodes.}

\section{Matériel biologique.}

Des chondrocytes ont été isolés à partir de cartilage de croissance de lapin ef mis en culture (Corvol, Dumontier et Rappaport, 1975). Après 20 jours de culture, les cellules ont cessé de se multiplier, elles se sont empilées en colonnettes reproduisant la morphologie des chondrocytes de cartilage de croissance in vivo et elles synthétisent les protéoglycannes soufrés spécifiques de ce type cellulaire. On peut étudier ainsi sur ces chondrocytes vivants la synthèse protéique globale par la mesure de l'incorporation d'un acide aminé marqué tel la leucine ${ }^{14} \mathrm{C}$. La mesure de la synthèse protéique spécifique de ces cellules se fait après incorporation de soufre radioactif dans les cellules. Les protéoglycannes soufrés sont alors isolés et purifiés dans le milieu de culture et dans les chondrocytes.

Des fibroblastes isolés à partir de fragments de peau ont été mis en culture de la même manière.

\section{Métabolites de la vitamine $D_{3}$.}

a) Pour l'étude du métabolisme, le $\left[25,26-{ }^{3} \mathrm{H}\right] 25-(\mathrm{OH}) \mathrm{D}_{3}$ (the Radiochemical Centre, Amersham, England, $10 \mathrm{Ci} / \mathrm{mM}$ ) a été ajouté au milieu de culture des chondrocytes dans $0,02 \mathrm{ml}$ d'éthanol ;

b) Pour l'étude de l'activité biologique, la vitamine $D_{3}$, le $25-(O H) D_{3}$ ef le 24,25 $(\mathrm{OH})_{2} \mathrm{D}_{3}$ synthétiques ont été ajoutés au milieu de culture dans $0,02 \mathrm{ml}$ d'éthanol en utilisant des concentrations de $10^{-14} \mathrm{M}$ à $10^{-7} \mathrm{M}$. L'activité de ces produits sur l'augmentation in vivo de la calcémie de rats carencés en calcium et en vitamine $D$ a été vérifiée avant l'incubation. 
Des quantités suffisantes du dérivé du $25-(\mathrm{OH}) \mathrm{D}_{3}$ ont pu être produites au cours d'incubation de cartilage. L'activité biologique de ce dérivé a été testée après purification à l'aide des systèmes chromatographiques décrits plus loin et après vérification de sa sensibilité au traitement par le périodate de sodium.

\section{Ełude du métabolisme.}

Les cellules ont été incubées à $37^{\circ} \mathrm{C}$, pendant $15 \mathrm{mn}$ à $6 \mathrm{~h}$, sous 95 p. 100-5 p. 100 Air- $\mathrm{CO}_{2}$ en présence de $8.10^{-9} \mathrm{M}$ de ${ }^{3} \mathrm{H}-25-(\mathrm{OH}) \mathrm{D}_{3}$. Les cellules ont été récupérées par grattage à la fin de l'incubation, puis lavées du milieu dans du sérum physiologique et homogénéisées. Après extraction dans un mélange chloroforme-méthanol, la phase chloroformique, contenant le $25-(\mathrm{OH}) \mathrm{D}_{3}$ et ses dérivés solubles dans le chloroforme a été chromatographiée sur Sephadex LH 20 pour en dissocier les constituants. Les comportements chimiques et chromatographiques des éventuels dérivés formés du $25-(\mathrm{OH}) \mathrm{D}_{3}$ ont été comparés à ceux des dérivés connus de cette molécule : 24,25 et 1,25-dihydroxycholécalciférol, 1,24,25-trihydroxycholécalciférol. Le matériel migrant dans la région du $24,25-(\mathrm{OH})_{2} \mathrm{D}_{3}$ a été repris et chromatographié sur un appareil Dupont de Nemours, modèle 841, en utilisant une colonne ODS-Permaphase et un gradient d'élution de 80 à 100 p. 100 de méthanol dans l'eau. La chromatographie en phase liquide à haute pression a été répétée deux fois encore avant l'éłude de la sensibilité de ce produit au traitement par le périodate de sodium selon la technique décrite (Knutson et Deluca, 1974).

\section{Résultats.}

\section{Métabolisme du 25-(OH) $\mathrm{D}_{3}$.}

Après incubation des chondrocytes, il est possible d'isoler par chromatographie divers dérivés tritiés du $25-(\mathrm{OH}) \mathrm{D}_{3}$. L'un des produits de transformation comigre avec du 24,25-dihydroxycholécalciférol synthétique dans deux systèmes de chromatographie :

- le gel de Sephadex LH 20 avec comme éluant un mélange de chloroforme et d'hexane $65: 35$;

- la chromatographie en phase liquide à haute pression.

Nous avons vérifié que ce dérivé n'apparaît en aucun cas lorsque le 25-hydroxycholécalciférol est incubé dans le milieu seul, ce qui rend difficile l'hypothèse d'une dégradation du 25-hydroxycholécalciférol en son produit plus polaire pendant l'incubation. De plus, ce produit plus polaire n'apparaît pas lors des incubations du 25-hydroxycholécalciférol en présence de fibroblastes en culture. Dans les chondrocytes, il apparaît dès la $15 \mathrm{e}$ minute d'incubation du $25(\mathrm{OH}) \mathrm{D}_{3}$ dans les cellules ef sa formation atteint un plateau vers la $60^{\mathrm{e}}$ minute (fig. 1).

La sensibilité de ce dérivé à l'oxydation par le périodate de sodium est comparable $(80$ p. 100$)$ à celle du $24,25-(\mathrm{OH})_{2} \mathrm{D}_{3}$ synthétique.

2. Activité des métabolites de la vitamine $D$.

Une activité biologique du $25-(\mathrm{OH}) \mathrm{D}_{3}$ peut être mise en évidence sur la synthèse des protéines soufrées spécifiques dans les chondrocytes de lapins en culture. La vita- 
mine $D_{3}$ ne semble avoir aucune activité dans ce système ; par contre le $24,25-(\mathrm{OH})_{2} \mathrm{D}_{3}$ synthéfique a une activité 100 à 1000 fois plus grande que le $25-(\mathrm{OH}) \mathrm{D}_{3}$. La dose active pour le $24,25-(\mathrm{OH})_{2} \mathrm{D}_{3}$ se situe entre 0,1 ef $10 \mathrm{pg}$ par $\mathrm{ml}$ de milieu de culture (tabl. 2). Dans le même système, le produit isolé à partir des incubations de tissu carti-

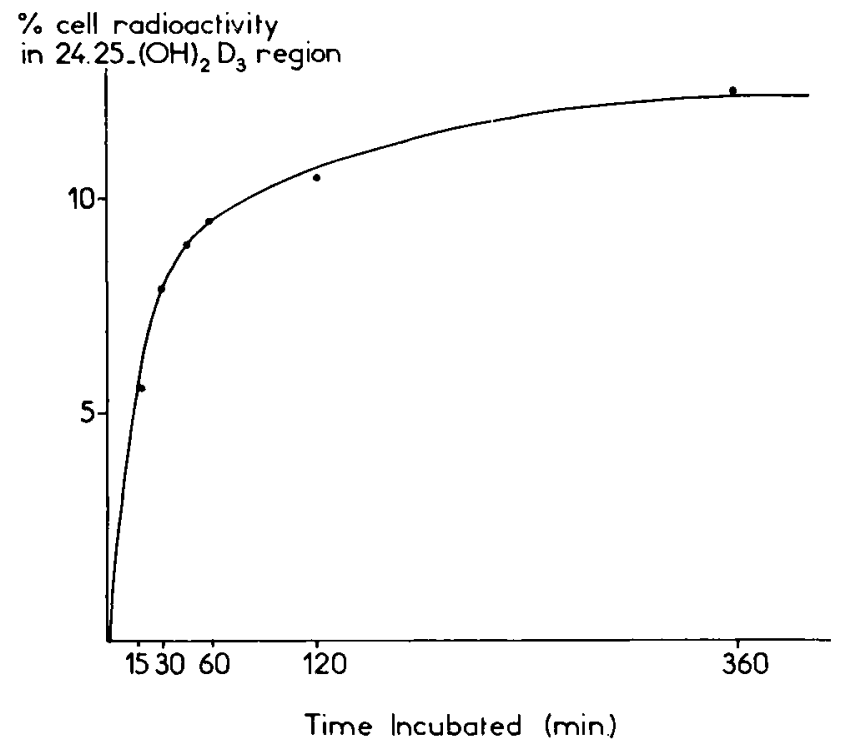

FIG. 1. - Pourcentage de la radioactivité cellulaire migrant dans la région du $24,25-(\mathrm{OH})_{2} \mathrm{D}_{3}$ en fonction du temps d'incubation (en min.). Les chondrocytes en culture ont été incubés en présence de $\left[25,26-{ }^{3} \mathrm{H}\right]$ 25- $(\mathrm{OH}) \mathrm{D}_{3}\left(8.10^{-9} \mathrm{M}\right)$ pendant 15 à $360 \mathrm{mn}$. Après extraction des cellules dans un mélange chloroforme-méthanol, la phase chloroformique a été chromatographiée sur gel de Sephadex LH 20.

\section{TABLEAU 2}

Effets de la vitamine $D_{3}$ et de ses métabolites sur l'incorporation de ${ }^{35} \mathrm{SO}_{4}$ dans la fraction non dialysable du milieu de culture des chondrocytes

\begin{tabular}{ccccc}
\hline $\begin{array}{c}\text { Concentrations } \\
\text { (Molarité) }\end{array}$ & Vitamine $\mathrm{D}_{3}$ & $25-(\mathrm{OH}) \mathrm{D}_{3}$ & $24,25-(\mathrm{OH})_{2} \mathrm{D}_{3}$ & $\begin{array}{c}\text { Dérivé du 25-(OH) } \mathrm{D}_{3} \\
\text { du cartilage }\end{array}$ \\
\hline Témoins & $3.08 \pm 0.18\left(^{(1)}\right.$ & $2.35 \pm 0.24$ & $2.35 \pm 0.24$ & $2.35 \pm 0.24$ \\
$2.5 \times 10^{-14}$ & $3.12 \pm 0.18$ & $2.44 \pm 0.20$ & $2.38 \pm 0.18$ & $2.33 \pm 0.18$ \\
$2.5 \times 10^{-13}$ & $\overline{-}$ & $2.31 \pm 0.25$ & $3.63 \pm 0.18 * *$ & $3.59 \pm 0.20^{* *}$ \\
$2.5 \times 10^{-12}$ & $2.91 \pm 0.24$ & $2.50 \pm 0.18$ & $3.91 \pm 0.20^{* *}$ & $3.93 \pm 0.20^{* * *}$ \\
$2.5 \times 10^{-11}$ & - & $2.52 \pm 0.20$ & $3.84 \pm 0.17 * * *$ & $3.81 \pm 0.18 * *$ \\
$2.5 \times 10^{-10}$ & - & $2.50 \pm 0.18$ & $2.41 \pm 0.20$ & $2.36 \pm 0.22$ \\
$2.5 \times 10^{-9}$ & $2.92 \pm 0.18$ & $2.45 \pm 0.20$ & $2.52 \pm 0.19$ & $2.35 \pm 0.20$ \\
$2.5 \times 10^{-8}$ & $3.05 \pm 0.25$ & $3.05 \pm 0.20 *$ & $2.45 \pm 0.21$ & $2.28 \pm 0.24$ \\
$2.5 \times 10^{-7}$ & $3.07 \pm 0.20$ & $2.54 \pm 0.19$ & $2.51 \pm 0.20$ & $2.32 \pm 0.18$ \\
& & & & \\
\hline
\end{tabular}

(1) Moyenne $\pm \mathrm{SD}$ de 5 flacons de culture, exprimée en $\mathrm{dpm} \times 10^{-4} / \mu \mathrm{g}$ DNA.

Les valeurs significativement différentes de celles des contrôles sont notées : * $p<0.05$; ** $p<0.01 ; * * * p<0.001$. 
lagineux, possède une activité biologique comparable à celle du $24,25-(\mathrm{OH})_{2} \mathrm{D}_{3}$, bien supérieure à celle du précurseur 25-hydroxycholécalciférol.

\section{Discussion.}

Ces résultats montrent que les cellules cartilagineuses in vitro sont capables de transformer le 25-hydroxycholécalciférol en un métabolite plus polaire qui a pu être isolé, en un seul pic, dans deux systèmes de chromatographie. Trois séries de faits arguent en faveur de l'identité de ce produit avec le 24,25-dihydroxycholécalciférol :

- un comportement identique dans deux systèmes chromatographiques, maintenant classiques pour les métabolites de la vitamine $D$;

— une sensibilité semblable à l'oxydation par le périodate de sodium ;

- une activité biologique comparable sur l'incorporation de soufre marqué dans les protéines soufrées sécrétées par les chondrocytes en culture.

Les cellules du tissu cartilagineux pourraient donc posséder un système enzymatique capable de transformer le $25-(\mathrm{OH}) \mathrm{D}_{3}$ en $24,25-(\mathrm{OH})_{2} \mathrm{D}_{3}$ ef le cartilage serait un des lieux de formation du $24,25-(\mathrm{OH})_{2} \mathrm{D}_{3}$ retrouvé chez les patients anéphriques. Chez ces malades, la présence de quantités circulantes de $24,25-(\mathrm{OH})_{2} \mathrm{D}_{3}$, même faibles, montre que l'activité de la $25-(\mathrm{OH}) \mathrm{D}_{3}$-24-hydroxylase extra-rénale n'est pas négligeable. Son importance dans le métabolisme de la vitamine $D$ reste cependant à préciser.

Les chondrocytes ne semblent pas être seulement le siège d'une transformation du $25-(\mathrm{OH}) \mathrm{D}_{3}$, ils sont peut-être aussi un site d'action du dérivé formé. En effet, le $24,25-(\mathrm{OH})_{2} \mathrm{D}_{3}$ possède in vitro une grande activité sur la stimulation de l'incorporation du soufre marqué dans les protéoglycannes. Quelle qu'en soit la signification, l'effet in vitro du 24,25-(OH $)_{2} \mathrm{D}_{3}$ sur le métabolisme des chondrocyłes est retrouvé pour des concentrations très faibles de ce métabolite (de l'ordre du picogramme par millilitre de milieu).

Le 25-(OH) $D_{3}$ est également actif dans ce système, mais les concentrations requises pour obtenir cet effet sont mille fois plus élevées, de l'ordre du nanogramme par millilitre de milieu. L'observation de sa transformation in vitro en un dérivé beaucoup plus actif laisse supposer que cette transformation est un préalable nécessaire à l'activité du $25-(\mathrm{OH}) \mathrm{D}_{3}$ sur l'incorporation du ${ }^{35} \mathrm{SO}_{4}$ dans les protéoglycannes.

Le rôle physiologique du $24,25-(\mathrm{OH})_{2} \mathrm{D}_{3}$ est encore inconnu. Jusqu'à présent, aucun test n'a permis de démontrer une activité du $24,25-(\mathrm{OH})_{2} \mathrm{D}_{3}$ plus grande que celle du 25-(OH) $D_{3}$ (Deluca, 1976). L'incorporation du soufre par les chondrocytes in vitro pourrait donc fournir un test sensible d'activité biologique pour le $24,25-(\mathrm{OH})_{2} \mathrm{D}_{3}$. 


\section{Références}

CORVOL M. T., DUMONTIER M. F., RAPPAPORT R., 1975. Culture of chondrocytes from the proliferative zone of epiphyseal growth plate cartilage from prepubertal rabbits. Biomedicine, 23, $101-107$.

DELUCA H. F., 1976. Recent advances in our understanding of the vitamin D endocrine system. J. Lab. clin. Med., 87, 7-26.

GARABEDIAN M., PAVLOVITCH H., FELLOT C., BALSAN S., 1974. Metabolism of 25-hydroxyvitamin $D_{3}$ in anephric rat : a new active metabolite. Proc. nat. Acad. Sci., USA, 71, 554-557.

GARABEDIAN M., PEZANT E., CORVOL M. T., BAILLY DU BOIS M., BALSAN S., 1976. The cartilage tissue : role in vitamin D metabolism. Abstr. 2nd int. workshop on Calcified Tissues. Israel J. med. Sci., 12, 22.

GRAY R. W., WEBER H. P., DOMINGUEZ J. H., LEMANN J., 1974. The metabolism of vitamin $D_{3}$ and 25-hydroxyvitamin $D_{3}$ in normal and anephric humans. J. clin. Endocr. Metab., 39, 1045-1056.

KNUTSON J. C., DELUCA H. F., 1974. 25-hydroxyvitamin $D_{3}$-24-hydroxylase. Subcellular localisation and properties. Biochemistry, 13, 1543-1548.

PREECE M. A., O'RIORDAN J. L. H., LAWSON D. E. M., KODICEK E., 1974. A competitive protein-binding assay for 25-hydroxycholecalciferol and 25-hydroxyergocalciferol in serum. Clin. chim. Acta, 54, 235-242. 